This is an electronic reprint of the original article. This reprint may differ from the original in pagination and typographic detail.

Author(s): Okkolin, Mari-Anne; Lehtomäki, Elina; Bhalalusesa, Eustella

Title: $\quad$ The Successful Education Sector Development in Tanzania - Comment on genderbalance and inclusive education

Year: $\quad 2010$

Version:

Please cite the original version:

Okkolin, M.-A., Lehtomäki, E., \& Bhalalusesa, E. (2010). The Successful Education Sector Development in Tanzania - Comment on gender-balance and inclusive education. Gender and Education, 22(1), 63-71.

https://doi.org/10.1080/09540250802555416

All material supplied via JYX is protected by copyright and other intellectual property rights, and duplication or sale of all or part of any of the repository collections is not permitted, except that material may be duplicated by you for your research use or educational purposes in electronic or print form. You must obtain permission for any other use. Electronic or print copies may not be offered, whether for sale or otherwise to anyone who is not an authorised user. 


\title{
Comment and critique
}

\section{The Successful Education Sector Development in Tanzania - Comment on gender-balance and inclusive education}

\author{
Mari-Anne Okkolin ${ }^{\mathrm{a}^{*}}$, Elina Lehtomäki ${ }^{\mathrm{a}}$ and Eustella Bhalalusesa ${ }^{\mathrm{b}}$ \\ a'University of Jyväskylä, Finland; ${ }^{b}$ University of Dar es Salaam, Tanzania
}

In this paper we discuss to what extent the international and national equality goals regarding gender-balance and inclusive education have been reached in the education sector development in Tanzania. According to recent reports, the development trend has been generally positive, and the country is close to achieve its primary education targets. More detailed reviews suggest, however, that current monitoring and evaluation mechanisms are too narrow to catch the critical factors regarding equality, particularly in secondary education. Our comment concerns the achievements and challenges, and emphasises the significance of multidimensional set of information including in-depth qualitative research on connections between socio-cultural factors and education.

Keywords: Education; Gender; Disability; Inclusive education; Tanzania;

Educational outcomes

Total number of words: 4700

\footnotetext{
*Corresponding author. Email: mari-anne.okkolin@yfi.jyu.fi
} 
The Successful ESD in Tanzania

\section{Equity and non-discrimination policies in the education sector development}

The World Declaration on Education For All in 1990 and the Dakar Framework for Action of 2000 draw on the Universal Human Rights and aim at ensuring equal opportunities to education. Reports on marginalisation and exclusion of girls and women have urged the international community to set targets for universal primary education for all and gender balance in all levels of education. Two of the Millennium Development Goals, approved by world leaders in 2000 and by the UN World Summit in 2005, define equality in education as a means to poverty reduction. The UN Convention on the Rights of Persons with Disabilities of 2006 further assures the universal right to inclusive education systems without discrimination on the basis of disability, and defines the situation of girls and women with disabilities as particularly vulnerable to marginalisation and exclusion. According to the Convention schools are to be enabling environments for all. The global declarations and processes have led to regional and national strategies and plans. In general, gender balance has become an important strategic goal, while less attention has been paid to inclusion of persons with disabilities. Still, conceptually both issues fall under the internationally agreed goals and targets for equality in education.

The government of the United Republic of Tanzania (URT) has defined education a national priority in two key policies, the Tanzania Development Vision 2025 and in the National Strategy for Growth and Reduction of Poverty. In line with the Millennium Development Goals and Education For All process, the government is committed to equity and non-discrimination policies in education and has initiated a series of reforms to ensure equal access to primary education of good quality for all children, to expand secondary education, and to promote education and empowerment of girls. The National Policy on Disability of 2004 defines education as key to development of potentials and self-reliance of people with disabilities. They have the right to receive the same services from the society as the non-disabled people, and the government is to ensure participation, integration and equal opportunities for persons with disabilities. The policy document points out, however, that despite the commitment the education system is not inclusive.

Tanzanian education sector monitoring and evaluation reports have drawn our attention to indicators of and reporting on implementation of the equity and nondiscrimination policies. In this paper we describe the recent education sector reforms 
and explore previous studies and education sector development documentation in order to highlight the achievements regarding gender-balance and inclusiveness. We discuss how gender balance has been addressed in the latest primary and secondary education development programmes, and look at inclusion of persons with educational special needs and disabilities. We conclude by commenting on the education sector development monitoring and reporting mechanisms.

\section{Achieving gender-balance and inclusiveness in primary education?}

Universal primary education has been the goal of Tanzanian education policies since 1975, and the Education Act of 1978 made primary education compulsory, though not free. Reflecting the commitments formulated by the UN conferences and other international summits of the 1990s, gender equality is recognised as a development goal per se and moreover, as a cross-cutting issue in sustainable social development and poverty reduction process. Inclusion of persons with disabilities has been addressed in the national level policies in 2004. Different from clearly set goals for gender balance, inclusion of persons with disabilities in education lack strategies and targets. The differences in approaches to the two equality components are discussed below.

The 2002 Primary Education Development Plan (PEDP) was the first outcome of the efforts to turn international education obligations into feasible strategies and actions. Enrolment Expansion was the highest priority of the PEDP, which aimed at all children aged $7-13^{1}$ being enrolled in primary education by 2005 . According to the Basic Education Statistics in Tanzania, the 2007 gross enrolment rate reached 114,4\% and the attained net enrolment ratio was 97\%. Enrolment ratios were approximately equal between girls and boys: in 2007 the net enrolment ratio for girls was 97\%, compared to $97,6 \%$ for boys. Furthermore, gender parity was reported to be almost 1:1 in all the regions (URT, 2007).

\footnotetext{
${ }^{1}$ The Tanzanian education system defines seven years of primary education, Standards I-VII, free for all. Transition to secondary schools depends on selection process assessing primary school learning achievements. Secondary education consists of four years in Ordinary level (O-level), Forms I-IV; and Advanced level (A-level) of two years, Forms V-VI.
} 
Regarding its highest priority, increase of the overall gross and net enrolment of girls and boys, the PEDP has unquestionably been a success. The generally very positive trend is still challenged by more analytical reports. Carr-Hill and Ndalichako (2005) have pointed out that the current concerns are regional inequalities, difficulty of enrolling the remaining children, and relatively high dropout and repetition rates (see also HakiElimu, 2005). There were more than 350000 repeaters in 2007, though the number had decreased from the previous years. Both repetition and dropout rates were highest in Standard I-II and in Standard IV-V. This suggests that experiences from the first years are crucial for motivating learning and decisions regarding schooling. On the basis of the high net enrolment rates it could be assumed that also children with disabilities were enrolled, though the report on a small number of children with disabilities does not support this assumption.

During the PEDP implementation there were changes in performance. In 2006, 80\% of the candidates passed the Standard IV Examinations, which was 9\% less than three years earlier. The trend in Primary School Leaving Examination (Standard VII) was vice versa. Year 2002 the passing rate was 27\%, in 2004 it was 49\%, and 2006 it rose up to 71\% of the candidates (URT, 2007). The decline in Examination pass rates in Standard IV, similarly to the high repetition and dropout rates in lower grades may be interpreted as a demand for early identification of risk factors and interventions, as well as improvement of quality of education in general.

In most schools in Tanzania, the significantly increased enrolment rates at Standard I have resulted in overcrowding, and children repeating years have further aggravated the problem. Repetition burdens all educational resources. According to previous studies lack of qualified and competent teachers, lack of teaching and learning facilities, parental attitudes and financial constraints were related to repetition and dropout (Gwimile 2005, in Carr-Hill and Ndalichako, 2005, 31). In primary schools the main reasons for dropout were truancy (76\%), followed by lack of school needs, pregnancy $(5,6 \%)$ and death. In absolute numbers there were three thousand girls /young women who left school at a very early age. (URT, 2007) The government called for an urgent remedy for truancy, though reasons behind truancy and connections between various factors were not analysed.

In order to improve the quality of education, the PEDP proposed recruiting a certain number of new teachers. More teachers were recruited than originally planned but still there was a shortage of teachers, which meant that the PEDP targets for 
recruitment were underestimated. The PEDP aimed at establishing teacher-to-pupil ratios (TPR) that could accommodate increases in enrolment rates. In 2007 the national average ratio was 1:53, though regional differences ranged from 1:41 in Dar es Salaam to 1:70 in Shinyanga (URT, 2007). The government re-estimated that it would take five years to clear the backlog of teacher demand in the primary education. During the first years of the PEDP implementation, efforts were made to ensure an equitable and gender balanced distribution of trained teachers. Overcoming regional disparities seemed to be a challenge, because the more qualified teachers tended to favour urban areas and female teachers were concentrated in urban schools.

In line with the National Policy on Disability the PEDP applied a social model to disability that focuses on the inadequacy of the schooling environment rather than on the individual special educational needs (Carr-Hill and Ndalichako, 2005). This is important for mainstreaming and inclusive approach in education. Similarly to gender balance, however, segregated data is required to confirm policy implementation in practise, and focused action may be necessary in order to respond to needs of children with disabilities, particularly of girls with disabilities. In comparison to the gendersegregated statistics that provide a clear overview of development towards gender balance in regions and different levels of education, data on children with disabilities is very limited.

The 2006 statistics included data on children aged 5-6 with disabilities by regions (URT, 2007). It shows an attempt to foresee future special educational needs in primary education, which is an important step towards inclusive education planning and service provision. According to the 2006 primary education statistics, 2146 pupils with some type of disability were enrolled; the biggest groups were children with physical, mental and hearing impairments. Other categories of the identified disabilities included children with albinism, autism, dumbness and visual impairments. (URT, 2007) This means that teachers, schools or local administrations were able to identify some of the traditional, severe or apparent types of disabilities among school children, or that these children were brought to school. In addition, there were centres for special needs in all the regions with the total number of children attending the centres being 13059 $(\mathrm{M}=6607, \mathrm{~F}=6452)$.

Five regions (5/21) reported that they had reached a NER above 99\% in primary education (URT 2007), thus suggesting that they succeeded to provide education for all. Their reports on enrolment of children with disabilities do not support the assumption of 
including all. Small absolute numbers of children with severe disabilities without reference to prevalence rates, age group and performance provide a blur picture of the inclusion in practise, and challenge the overall high enrolment rates. The unclear information raises several questions in relation to the lack of goals and strategies. According to the national statistics 97\% of all children are enrolled, if so, are children with disabilities counted in the age group? Are they in school? Or are they the ones who repeat and dropout? The repetition and dropout rates are high, and have increased along with the enrolment rates. How capable and equipped are teachers and school leaders to recognise children at risk of repetition and dropout, marginalisation and exclusion?

\section{Achieving gender-balance and inclusiveness in secondary education?}

In Tanzania, the increases in enrolment rates in primary schools called for expansion of secondary education. Similarly to other African countries, the Tanzanian secondary education system has faced serious challenges due to changes in society, economy and labour market. Furthermore, the importance of secondary education for sustainable socio-economic development and personal benefits has been recognised. Therefore, the Secondary Education Development Plan (SEDP) followed the PEDP in 2004. The overall goal of the SEDP was to increase the proportion of Tanzanian youth that completes secondary education with acceptable outcomes. The projections reached up to 2010 aiming at achieving 50\% primary-secondary transition rate.

The secondary education sector in Tanzania has been one of the smallest in SubSaharan Africa (UNESCO, 2007; Colglough et al., 2003). Since 2004, the net enrolment ratio has increased every year, from as low as 6 to 20,6 in 2007 (URT, 2007). Furthermore, only $17 \%$ of the students were enrolled at the official age (fourteen years). The net enrolment ratio for Ordinary (O-level) and Advanced level (A-level) separately were 20,7 and 0,9 respectively, which means that the number of students completing six years of secondary education was very small. As in primary education, the difference in enrolment rates between girls and boys remained quite small in the O-level. In A-level girls made up only $0,6 \%$ of the net enrolment ratio. (URT, 2007) The recent reports and studies have not provided data on transition from primary to secondary education, or from A-level to O-level.

The SEDP paid attention to the poor performance in the secondary education national examinations and, consequently, set an objective to improve the quality. The 
students' level of performance was improved, but girls tended to have lower passing rate than boys. Form VI examinations also unquestionably proved that the performance in all-boys-schools or all-girls-schools was better than the performance in co-education schools. (URT, 2007) During the first years of SEDP implementation the dropout rates increased and were highest in Form II, where an examination was introduced. As in primary education, truancy was reported as the leading cause of dropouts in secondary education, followed by pregnancy and lack of school needs. There was no policy on reentry of pregnant schoolgirls after delivery.

The SEDP paid attention to students with disabilities, though there were no specific objectives and strategies (URT, 2004; O-Saki and Njabili, 2003). According to Mboya and Mosha (2003), educational services to people with disabilities have increased significantly during the last two decades, but they still are inadequate and of poor quality. There were 18 secondary schools that enrolled students with disabilities, but less than $9 \%$ of students with disabilities continued in secondary education - and most of them were boys. Problems encountered by students were unfriendly and inaccessible learning environments, inadequacy of teachers and learning/teaching materials, fees and payments, and irrelevance of training programs to the future lives of the students. Inappropriate school construction and infrastructures were serious barriers to learning and participation in secondary education (DOLASED, 2005).

Similarly to education statistics, reports on students with disabilities have made no reference to learning difficulties, connections to repetition and drop-out, and schools as disabling environments. The significant vulnerability of girls and young women with disabilities is not mentioned, and measures taken to increase their educational opportunities are not described.

\section{Beyond sensitive approach - towards responsive strategies?}

According to the education sector reports, Tanzania will soon reach the universal primary education. Fairly, the Tanzanian initiatives and experiences have been applauded. The PEDP and SEDP have succeeded in expanding and improving education provision in Tanzania. In the generally very positive development trend the equality issues remain a challenge, particularly for secondary education. For reaching the government commitments, the Millennium Development Goals and Education For 
All goals, paying further attention is required to the question of the remaining, repeating and dropout children, and ensuring options for transition.

In Tanzania, from the perspective of gender equality transitions from primary to secondary education and to upper grades in secondary school seem critical points. The gender gap in primary education has been closed and girls continue to secondary school. In upper secondary school (A-level) boys still outnumber girls. Furthermore, when moving from lower to higher levels, the differences in achievements between boys and girls grow. In the Basic Education Statistics on secondary education students with disabilities disappear totally, which may mean that they are not given an opportunity after primary education, or that they do not continue education. These phenomena are not particularly Tanzanian characteristics but have been observed as a trend in a number of developing countries recently (e.g. UNRISD 2005; UNESCO 2007; UN 2008). Consequently e.g. the Task Force on Education and Gender Equality (UN Millennium Project 2005, 5) "notes that the achievement of Goal 3 requires strengthening postprimary education opportunities for girls.” The Education For All movement calls for an extended vision of basic education instead of the sole focus on Universal Primary Education. Furthermore, the movement reminds that inclusion means encompassing the marginalised and disadvantaged (UNESCO 2007). Girls and women with disabilities who have limited access to primary education and even less opportunities for secondary education belong to the most marginalised and disadvantaged.

In Tanzania, as across the developing world, school-related barriers to girls' participation in education consist of the poor quality of the learning environment, irrelevant curricula, long distance between home and school, shortage of female teachers as role models, sexual harassment and discriminative practises in school. In addition to the school-related factors, Odaga and Heneveld (1995) explained the poor outcomes of girls with three other categories of contributing factors: Political and institutional factors, Socio-economic factors and Socio-cultural factors. In Tanzania, the socio-economic and socio-cultural factors have been in policy level discussions over forty years; first they were raised soon after the country gained Independence (see e.g. Buchert, 1994; Odaga and Heneveld, 1995). Still, recent studies emphasise similar issues (Colclough et al. 2003). Our observation is that the education sector programmes and monitoring reports do acknowledge the socio-economic and socio-cultural factors but, the policy level initiatives are directed mostly to school environment. The 
importance of the multidimensionality of the enabling environment that reaches beyond education should be however, more clearly incorporated into strategies and practices.

According to Colclough and others (2003), in the Sub-Saharan Africa the most important causes for non-attendance or truancy and also for not being enrolled, were the direct costs of schooling, such as fees, uniforms and equipment. It was easier for boys to find work and contribute to or cover the costs, whereas girls had more domestic responsibilities; and therefore, their education was more costly. In addition to their conclusions underlining poverty and national economy, the researchers strongly emphasised that the education and schooling of girls is a far more complex issue. For instance, the demand for female labour at home is a factor defined socio-culturally rather than economically; and in rural areas traditions and social roles are more binding than in urban areas.

Similarly to gender-related questions, disability and special educational needs are socio-culturally constructed and understood. Therefore, education sector statistics require cross-checking with information from community-based sources, health care and rehabilitation, and organisations of persons with disabilities (compare Kabeer 1999). In Tanzania, five regions (5/21) reported very high rates of enrolment, though numbers of students with educational special needs were low. Loeb and Eide (2004) state that surveys in developing countries fail to cover mild and moderate disabilities. Low-income countries report disability prevalence rates below 5\%, while the rates range between $10 \%$ and $20 \%$ in high-income countries. This significant difference is evident in the Tanzanian education statistics that focus on children with severe disabilities and those who receive some form of special education, but ignore the students in mainstream schools without support and with minor disabilities. The omission may be due to unawareness of limitations, lack of information on the possibilities of improving participation, and fewer demands from people with disabilities.

Tanzania was among the first African countries to sign the UN Convention on the Rights of Persons Disabilities (The Secretariat of the African Decade of Persons with Disabilities, 2007; UN, 2007). The Convention emphasises that girls and women with disabilities are subject to multiple discrimination. Regardless of changes in policy level approach and legislation, the majority of people with disabilities still face discrimination (Swain et al., 2004). Recent reviews of the Millennium project and poverty reduction strategies have pointed out that due attention has to be paid to the poorest of the poor, people with disabilities (Wiman and Sandhu, 2004; Yeo and Moore, 
2003). The UN Convention on Persons with Disabilities and the Education For All process define the overall goals for educational and social inclusion. Reaching the educational margins and particularly people facing multiple risks of marginalisation, like girls and women with disabilities, require detailed information to confirm inclusion in practise.

In Tanzania, regions and districts differ significantly, not only in attendance and school achievements, but moreover, in education management capacity and sociocultural interpretations of the relevance and meaning of education. Therefore, in order to address the multidimensional equality issues of gender and disability, local interpretations of the critical points such as truancy, remaining non-attending children and transitions are required. Furthermore, differences in achievements call for more detailed accounts of equality and quality in the teaching-learning process, participation and assessment. Assuming that EFA goals will be reached by policy-level mainstreaming without focused approaches and research on margins, the goal may be limited to education for almost all, and almost all over the country.

In general, the criticism of the Millennium Development Goals and Education For All emphasises the need for qualitative approach to assess the processes, the quality of education and its impact on participation and attainment. Unterhalter (2005) states that statistics on access and achievements provide a rather limited view on equality in education, and calls for a broader set of information and strategic engagement in order to achieve the Millennium Development Goals and Education For All targets; and supports initiatives of curriculum and pedagogical interventions, and stakeholder dialogue. Saith (2006) is even more critical, and suggests that the Goals are a mere global list of wishes. For instance, the change in education is monitored by focusing on the enrolment rates and sex parity in primary education; ignoring the high repetition and dropout rates, the quality of outcomes, and the resources allocated per child. While the Goal III is rather general and broad in scope, the insufficient conceptualisation has led to limited operationalisations and narrow indicators. This observation is in line with other previous research suggesting that international policies influence national policies, but have little impact in practise (Dale, 1999; Eleweke and Rodda, 2002; Dei et al., 2006). Likewise, many women's human rights advocates are concerned that the more far-reaching obligations and commitments embodied in CEDAW and Beijing Platform for Action are poorly reflected in the targets and indicators at the national level (United Nations Development Fund for Women, 2004). 
In order to study achievements and challenges regarding gender and disability in the education sector development, we suggest using a broader set of information and indepth monitoring that complements, confirms or contradicts statistics. Analysing schooling as a social arrangement that is to enable and empower girls, pays attention to agencies, institutions and social relations at various levels (Unterhalter 2003). Looking at education in its wider socio-cultural context can disclose factors out of the scope and mandate of education policies and schooling, which contribute to inequalities in education (e.g. King et al. 2005; Okkolin and Lehtomäki 2005; Unterhalter 2005). Consequently, in addition to quantitative indicators and data, implementation of education sector programmes is to be judged by their effects on individual human beings, and assessed from the perspectives of girls, including girls with disabilities, their families and communities (see e.g. Terzi, 2005; King et al., 2007; Walker and Unterhalter, 2007). There are communities successfully implementing equity policies, and what is more important, families who find ways of addressing or removing barriers to educating their girls. By studying and understanding these processes, i.e. why and how some communities and families have removed adverse cultural practices on the education and schooling of girls, including girls with disabilities, we could bring valuable insights to complement current discussions on policy and strategy.

In their much quoted paper, Naila Kabeer and Ramya Subrahmanian (1996) make a distinction between gender-blind and gender-aware policies, and categorise the latter further to gender-neutral, gender-specific and gender-transformative policy interventions. They point out that transformative interventions are politically the most challenging ones, and entail strategic thinking and a grounded sense of what is possible (ibid.). Our interpretation is that in Tanzania the positive development trend could be more gender-transformative and further enhanced, and the remaining obstacles removed by systematically adding socio-cultural dimensions into the monitoring and evaluation mechanisms. Accounts of girls, including girls with disabilities, who have successfully pursued educational careers, would provide valuable information about the critical factors beyond the political level of the educational establishment. Taking into consideration the needs, interests and views of girls, including girls with disabilities, would mean moving from gender-sensitive political acknowledgement to genderresponsive strategies and practices. 
The Successful ESD in Tanzania

\section{References}

Buchert, L. 1994. Education in the Development of Tanzania 1919-1990. Currey, London, UK.

Carr-Hill, R. and J. Ndalichako. 2005. Education Sector Situation Analysis. Final Draft Report Revised. Tanzania.

Colclough, C., S. Al-Samarrai, P. Rose, M. Tembon. 2003. Achieving Schooling for All in Africa: Costs, Commitment and Gender. Ashgate, Hants UK.

Dale, R. 1999. Specifying globalization effects on national policy: a focus on the mechanisms. Journal of Education Policy 14 (1), 1-17.

Dei, G.J.S., A. Asgharzadeh, S.E. Bahador and R.A. Shahjahan. 2006. Schooling and Difference in Africa. Democratic Challenges in a Contemporary Context. University of Toronto Press. Canada.

DOLASED (Disabled Organisation for Legal Affairs and Social Economic Development). 2005. The Research in the Status of Disabled Children's Rights in Tanzania: Access to Education Perspective. DOLASED Tanzania, Dar es Salaam.

Eleweke, C.J. and M. Rodda. 2002. The challenge of enhancing inclusive education in developing countries. International Journal of Inclusive Education 6 (2), 113126.

HakiElimu. 2005. Three Years of PEDP Implementation: Key Findings from Government Reviews. Dar es Salaam. Tanzania.

Kabeer, N. and R. Subrahmanian. 1996. Institutions, relations and outcomes: Framework and tools for gender-aware planning. Discussion Paper 357. Institute of Development Studies, University of Sussex. UK.

Kabeer, N. 1999. Resources, agency, achievements: Reflections on the measurement of women's empowerment. Development and Change. 30, 435-464.

King, K., R. Palmer and R. Hayman. 2005. Bridging research and policy on education, training and their enabling environments. Journal of International Development 17 (6), 803-817 (special issue).

King, K., S. McGrath and P. Rose. 2007. Beyond the basics: Educating and training out of poverty. International Journal of Educational Development 27 (4), 349-357.

Loeb, M. and A.H. Eide. 2004. Exploring living conditions among people with disabilities in southern areas of Africa. In Tøssebro, J. and A. Kittelsaa. (Eds.) Exploring the Living Conditions of Disabled People, Studentlitteratur, Lund, 65-82.

Mboya, M. and E.J. Mosha. 2003. Baseline Survey on Situation of the Disabled in Tanzania, An activity report leading to the implementation of programs of the "African Decade of Disabled People in Tanzania 2000-2009". SHYVYAWATA, Dar es Salaam.

Odaga, A. and W. Heneveld. 1995. Girls and School in Sub-Saharan Africa, From Analysis to Action. World Bank Technical Paper 298, Africa Technical Department.

Okkolin, M-A. and E. Lehtomäki. 2005. Gender and disability - Challenges of education sector development in Tanzania. In Hietanen, O. (Ed.) University Partnerships for International Development, Finnish development knowledge. Turku School of Economics and Business Administration. Finland Futures Research Centre publications 6, pp. 204-216.

O-Saki, K.M. and A.F. Njabili. 2003. Secondary Education Sector Analysis. Consultancy Report submitted to the Ministry of Education and Culture (Tanzania) and World Bank. 
Saith, A. 2006. From universal values to Millennium Development Goals: Lost in translation. Development and Change 37 (6), 1167-1199.

The Secretariat of the African Decade of persons with Disabilities. 2007. African countries to sign the new convention. Newsletter, 30 March http://www.secretariat.disabilityafrica.org (December 2007)

Swain, J., S. French, C. Barnes and C. Thomas. 2004. Disabling Barriers, Enabling Environments. Sage, London.

Terzi, L. 2005. Beyond the dilemma of difference: The capability approach to disability and special educational needs. Journal of Philosophy of Education 39 (3), 443459.

UN. 2007. Convention on the Rights of Persons with Disabilities. Resolution adopted by the General Assembly 61/106, http://www.un.org/disabilities/convention

UN 2008. The Millennium Development Goals Report.

UNESCO. 2007. Education For All. Global Monitoring Report. Education for All by 2015, We'll we make it?

United Nations Development Fund for Women. 2004. Pathway to Gender Equality. CEDAW, Beijing and the MDGs. UNIFEM in cooperation and with support of the GTZ sector project “Strengthening Women's Rights” on behalf of the German Federal Ministry for Economic Cooperation and Development.

UN Millennium Project, 2005. Taking Action: Achieving Gender Equality and Empowering Women. Task Force on Education and Gender Equality. Earthscan, London, UK.

UNRISD. 2005. Gender Equality. Striving for Justice in an Unequal World. United Nations Research Institute for Social Development.

URT (The United Republic of Tanzania). 2001. Primary Education Development Plan. The Ministry of Education and Culture, Dar es Salaam.

URT. 2004. Secondary Education Development Plan. The Ministry of Education and Culture, Dar es Salaam.

URT. 2007. Basic Education Statistics in Tanzania (BEST). 2003-2007 National Data. The Ministry of Education and Culture, Dar es Salaam.

Unterhalter, E. 2003. Crossing disciplinary boundaries: the potential of Sen's capability approach for sociologist of education. Review essay. British Journal of Sociology of Education 24 (5), 665-669.

Unterhalter, E. 2005. Global inequality, capabilities, social justice: The Millennium development goal for gender equality in education. International Journal of Educational Development 25 (2), 111-122.

Walker, M. and E. Unterhalter (Ed.) 2007. Amartya Sen's Capability Approach and Social Justice in Education. Palgrave Macmillian.

Wiman, R. and J. Sandhu. 2004. Integrating Appropriate Measures for People With Disabilities in the Infrastructure Sector. Helsinki, GTZ \& STAKES.

Yeo, R. and K. Moore. 2003. Including Disabled People in Poverty Reducation Work:”Nothing about us, without us”. World Development 31 (3), 571-590. 